\title{
Bactericidal activity of three different antiseptic ophthalmic preparations as surgical prophylaxis
}

\author{
Daniele Tognetto ${ }^{1}$ Marco R. Pastore ${ }^{1} \cdot$ Gian Marco Guerin ${ }^{1} \cdot$ Giuliana Decorti ${ }^{2,3} \cdot$ Martina Franzin $^{4}$. \\ Cristina Lagatolla ${ }^{5} \cdot$ Gabriella Cirigliano $^{1}$
}

Received: 24 May 2021 / Revised: 24 July 2021 / Accepted: 29 July 2021 / Published online: 24 August 2021

(c) The Author(s) 2021, corrected publication 2021

\begin{abstract}
Purpose In the era of antibiotic resistance, there is an increased interest in antiseptic solutions that might represent a reliable option for ocular surface disinfection. The objective of this study is to compare for the first time three different antiseptic ophthalmic preparations to assess their in vitro antimicrobial activity.

Methods The antiseptic activity of three commercial ophthalmic solutions, IODIM (povidone-iodine $0.6 \%$ in hyaluronic acid vehicle-Medivis, Catania, Italy), OZODROP (nanoemulsion with ozonated oil—concentration not specified—FBVision, Ophthalmic Pharmaceuticals, Rome, Italy), and DROPSEPT (chlorhexidine $0.02 \%$ and vitamin E $0.5 \%$ Tocopherol Polyethylene Glycol 1000 Succinate-TPGS, Sooft Italia, Montegiorgio, Italy), was tested in vitro on six reference strains by time-killing assays. Viable cells were evaluated after 1, 15, $30 \mathrm{~min} ; 2,6$, and $24 \mathrm{~h}$ exposure by seeding $100 \mu \mathrm{l}$ of the suspension (or appropriate dilutions) on LB agar or Sabouraud-dextrose agar. All plates were incubated at $37{ }^{\circ} \mathrm{C}$ for $24 \mathrm{~h}$ and evaluated by manually counting the colonies.

Results IODIM solution showed a very rapid microbicidal activity: the number of viable cells for all the tested strains was under the detection limit (less than $10 \mathrm{CFU} / \mathrm{ml}$ ) already after 1 min exposure, and this result was maintained at every incubation time. The rapid antimicrobial activity of povidone-iodine was not replicated when testing the other two antiseptics. Conclusions The study reports the great efficacy in reducing bacterial load in a very short time of povidone-iodine $0.6 \%$ compared with other antiseptic preparations.
\end{abstract}

Keywords Antiseptic $\cdot$ Microbicidal $\cdot$ Iodine $\cdot$ Ophthalmology $\cdot$ Ozone $\cdot$ Chlorhexidine $\cdot$ Infection

Marco R. Pastore

marco.pastore@hotmail.it

1 Department of Medical, Surgical Sciences and Health, Eye Clinic, University of Trieste, Piazza dell'Ospitale 1, 34129 Trieste, Italy

2 Institute for Maternal, Child Health IRCCS Burlo Garofolo, Trieste, Italy

3 Department of Medical, Surgical Sciences and Health, University of Trieste, Trieste, Italy

4 Science of Reproduction and Development, University of Trieste, Trieste, Italy

5 Department of Life Sciences, University of Trieste, Trieste, Italy 


\section{Key messages}

- Antibiotic resistance is a worldwide medical emergency that also affects the ophthalmology practice. The use of antiseptic solutions represents a reliable option for ocular surface disinfection.

- In this cross-sectional study, three different antiseptic ophthalmic preparations were tested on several microbial strains. Povidone-iodine showed a very rapid microbicidal activity: the number of viable cells for all the tested strains was under the detection limit (less than $10 \mathrm{CFU} / \mathrm{ml}$ ) already after $1 \mathrm{~min}$ exposure, and this result was maintained at every incubation time.

- We also found that the increased VDI of retinal capillaries was associated with photoreceptor loss.

\section{Introduction}

Nowadays, antibiotic resistance is a worldwide medical emergency that also affects the ophthalmology practice [1]. New resistance mechanisms are emerging and spreading globally, threatening our ability to treat common infectious diseases [2]. The antibiotic resistance crisis has been attributed to their overuse and misuse, and to the lack of new drug development by the pharmaceutical industry due to reduced economic incentives and challenging regulatory requirements [3].

Indeed, it is mandatory to achieve adequate antisepsis of the ocular surface in the pre-operative setting using both topical antibiotics and disinfectant ophthalmic solutions $[4,5]$.

Povidone-iodine (PVP-I) is an iodinated polyvinyl polymer used for years as a disinfectant and antiseptic agent, especially in pre-operative preparation of the skin and mucous membranes, as well as for the treatment of contaminated wounds [6]. The iodine molecules are free to oxidize vital pathogen structures such as amino acids, nucleic acids, and membrane components [7].

Currently, regimens for prophylaxis against postsurgical endophthalmitis include the use of PVP-I except in case of allergy [8-10]. Povidone-iodine is used worldwide due to its wide-spectrum antimicrobial activity, absence of resistant bacteria, and low cost. In a recent study, Musumeci et al. have demonstrated that PVP-I $0.6 \%$ has a more rapid bactericidal activity than PVP-I 5\%, due to the greater amount of free iodine when PVP-I is in low concentration [11].

Ozone is the most powerful oxidizing agent found in nature yet known in medicine for its antiseptic and antiinflammatory properties [12]. The introduction of oxidizing agents in drops for disinfection of the ocular surface is very recent. Their use has been advocated on the basis of efficacy against all microorganisms, as well as the lack of induction of antibiotic resistance [13]. The ozonated oil generates reactive oxygen species and lipid peroxidation products, which cause disruption of membrane layers, oxidation of nucleosides and aminoacids, and, ultimately, cell death [14]. To make it tolerated by the ocular surface, a nanoemulsion with ozonated oil within liposomes in solution with hypromellose and deionized water has been recently placed on the market (OZODROP, FBVision, Ophthalmic Pharmaceuticals, Rome, Italy) [15].

Chlorhexidine is an alternative antiseptic that was first employed in ophthalmology as a disinfectant for soft contact lenses and has been used to treat Acanthamoeba keratitis for more than 20 years $[16,17]$. It is a cationic biguanide that binds to and disrupts the bacterial cell wall leading to cytoplasmic damage and cell death. Chlorhexidine has been demonstrated to be effective when investigating ocular bacterial count after antisepsis $[16,18]$. In a multicentre retrospective case series using aqueous chlorhexidine, the endophthalmitis rate was $0.0074 \%$, which is comparable with povidone-iodine rates [19]. Although chlorhexidine compares well with povidone-iodine preparation, especially for patients intolerant of the latter, it is not sporicidal, and there are reports of reduced susceptibility in methicillinresistant Staphylococcus aureus and fungi [20-22]. A new preparation based on chlorhexidine was recently introduced on the market DROPSEPT (Sooft Italia, Montegiorgio, Italy). It is a $0.5 \%$ solution which includes vitamin $\mathrm{E}$ and Tocopherol Polyethylene Glycol 1000 Succinate.

The purpose of this study is to compare for the first time three different antiseptic ophthalmic preparations in order to assess their in vitro antimicrobial activity.

\section{Materials and methods}

In this experimental study, the antiseptic activity of three commercial ophthalmic solutions, IODIM (povidone-iodine $0.6 \%$ in hyaluronic acid vehicle), 
Table 1 Microbial growth at different times after exposure to povidone-iodine 0.6\% (IODIM)

\begin{tabular}{llllllll}
\hline & 0 & 1 ' & 15 , & 30 ' & $2 \mathrm{~h}$ & $6 \mathrm{~h}$ \\
\hline S. epidermidis ATCC 12228 & $6.25 \pm 0.19$ & No growth & No growth & No growth & No growth & No growth & No growth \\
S. aureus met $^{\mathrm{S}}$ ATCC 25923 & $6.56 \pm 0.03$ & No growth & No growth & No growth & No growth & No growth & No growth \\
S. aureus met $^{\mathrm{R}}$ ATCC 43300 & $6.62 \pm 0.20$ & No growth & No growth & No growth & No growth & No growth & No growth \\
E. coli ATCC 25922 & $6.30 \pm 0.08$ & No growth & No growth & No growth & No growth & No growth & No growth \\
P. aeruginosa ATCC 27853 & $6.43 \pm 0.10$ & No growth & No growth & No growth & No growth & No growth & No growth \\
C. albicans ATCC 90028 & $6.21 \pm 0.57$ & No growth & No growth & No growth & No growth & No growth & No growth \\
\hline
\end{tabular}

$m e t^{S}$ methicillin-susceptible; $m e t^{R}$ methicillin-resistant

OZODROP (nanoemulsion with ozonated oil-concentration not specified) [15], and DROPSEPT (chlorhexidine $0.02 \%$ and vitamin E TPGS 0.5\%) [23], was tested in vitro on the following reference strains: Staphylococcus aureus ATCC 25923 (methicillin-susceptiblemet $^{\mathrm{S}}$ ), Staphylococcus aureus ATCC 43,300 (methicillin-resistant- $\mathrm{met}^{\mathrm{R}}$ ), Staphylococcus epidermidis ATCC 12228, Pseudomonas aeruginosa ATCC 27853, Escherichia coli ATCC 25922, and Candida albicans ATCC 90028. Microbial strains were incubated overnight at $37{ }^{\circ} \mathrm{C}$ in LB broth (bacterial strains) or in Sabourauddextrose broth (Candida) and the optical density of the cultures was measured at $600 \mathrm{~nm}$. Based on growth curves previously obtained for each strain, microbial suspensions in phosphate buffered saline solution at a concentration of about $5 \times 10^{8}$ colony forming units $(\mathrm{CFU}) / \mathrm{ml}$ were prepared. Ten microliters of each suspension was added to $1 \mathrm{ml}$ of each ophthalmic solution to achieve a final concentration of about $5 \times 10^{6} \mathrm{CFU} /$ $\mathrm{ml}$. For the determination of the microbicidal activity, viable cells were evaluated at 1, 15, $30 \mathrm{~min} ; 2,6$, and $24 \mathrm{~h}$ by seeding $100 \mu \mathrm{l}$ of the suspension (or proper dilutions when needed) on LB agar or Sabouraud-dextrose agar. All plates were incubated at $37{ }^{\circ} \mathrm{C}$ for $24 \mathrm{~h}$ and evaluated by manually counting the colonies. All experiments were performed in triplicate and positive and negative controls were included in each experiment. Results were expressed as the mean value of the $\log _{10}$ $\mathrm{CFU} / \mathrm{ml} \pm$ standard deviation.

\section{Results}

The antiseptic activity of the three ophthalmic solutions against the tested strains was evaluated at different exposure times.

IODIM solution showed a very rapid microbicidal activity: the number of viable cells for all the tested strains was under the detection limit (less than $10 \mathrm{CFU} / \mathrm{ml}$ ) already after 1 min exposure, and this result was maintained at every incubation time (Table 1).

The rapid antimicrobial activity of PVP-I was not replicated when testing the other two antiseptics. As summarized in Table 2, liposome-vehiculated ozonated oil (OZODROP) showed a weak killing activity only after prolonged exposure against three out of the six tested strains. Indeed, after 24-h exposure, it reached, as best result, a reduction of about $2 \log _{10}$ of the CFUs for $S$. epidermidis and of 1 and $0.5 \log _{10}$ for E. coli and $P$. aeruginosa, respectively. No activity was detected against the two $S$. aureus strains and C. albicans.

Regarding the chlorhexidine-containing ophthalmic solution (DROPSEPT), a good antiseptic activity against $E$. coli was detected from 2-h exposure onwards, reaching a complete killing after $24 \mathrm{~h}$ (Table 3 ). A weaker activity was observed against the three staphylococci strains (1-2 $\log _{10}$ CFUs reduction at $24 \mathrm{~h}$ ), while $C$. albicans was not affected at all. For $P$. aeruginosa, the treatment showed a weak bactericidal activity after 2 - and 6-h exposure, causing a reduction of the CFUs of about $1.5 \log _{10}$ followed, at $24 \mathrm{~h}$, by a partial regrowth of the microorganism. However, this is

Table 2 Microbial growth at different times after exposure to nanoemulsion with ozonated oil (OZODROP)

\begin{tabular}{llllllll}
\hline & 0 & 1 & 15 & 30 & $2 \mathrm{~h}$ & $6 \mathrm{~h}$ & $24 \mathrm{~h}$ \\
\hline S. epidermidis ATCC 12228 & $6.31 \pm 0.26$ & $6.25 \pm 0.19$ & $6.13 \pm 0.24$ & $6.31 \pm 0.35$ & $6.25 \pm 0.10$ & $6.25 \pm 0.19$ & $4.63 \pm 0.45$ \\
S. aureus met $^{\mathrm{S}}$ ATCC 25923 & $6.56 \pm 0.03$ & $6.77 \pm 0.27$ & $6.81 \pm 0.26$ & $6.72 \pm 0.23$ & $6.72 \pm 0.09$ & $6.67 \pm 0.07$ & $6.57 \pm 0.23$ \\
S. aureus met $^{\mathrm{R}}$ ATCC 43300 & $6.62 \pm 0.20$ & $6.85 \pm 0.06$ & $6.67 \pm 0.05$ & $6.67 \pm 0.06$ & $6.87 \pm 0.12$ & $6.78 \pm 0.07$ & $6.55 \pm 0.27$ \\
E. coli ATCC 25922 & $6.57 \pm 0.30$ & $6.46 \pm 0.48$ & $6.43 \pm 0.27$ & $6.56 \pm 0.25$ & $6.57 \pm 0.22$ & $6.15 \pm 0.41$ & $5.41 \pm 0.19$ \\
P. aeruginosa ATCC 27853 & $6.29 \pm 0.54$ & $6.43 \pm 0.60$ & $6.46 \pm 0.57$ & $6.47 \pm 0.41$ & $6.62 \pm 0.11$ & $6.10 \pm 0.54$ & $5.66 \pm 0.19$ \\
C. albicans ATCC 90028 & $6.33 \pm 0.21$ & $6.30 \pm 0.06$ & $6.29 \pm 0.02$ & $6.37 \pm 0.07$ & $6.33 \pm 0.18$ & $6.32 \pm 0.00$ & $6.27 \pm 0.13$ \\
\hline
\end{tabular}

$m e t^{S}$ methicillin-susceptible; $m e t^{R}$ methicillin-resistant 
Table 3 Microbial growth at different times after exposure to chlorhexidine 0.02\% (DROPSEPT)

\begin{tabular}{llllllll}
\hline & 0 & 1 & 15 & 30 & $2 \mathrm{~h}$ & $6 \mathrm{~h}$ & $24 \mathrm{~h}$ \\
\hline S. epidermidis ATCC 12228 & $6.15 \pm 0.10$ & $6.15 \pm 0.12$ & $6.09 \pm 0.12$ & $5.94 \pm 0.31$ & $5.85 \pm 0.20$ & $5.66 \pm 0.12$ & $4.38 \pm 0.48$ \\
S. aureus met $^{\mathrm{S}}$ ATCC 25923 & $6.46 \pm 0.20$ & $6.79 \pm 0.16$ & $6.76 \pm 0.12$ & $6.61 \pm 0.20$ & $6.34 \pm 0.08$ & $6.37 \pm 0.10$ & $5.72 \pm 0.25$ \\
S. aureus met $^{\mathrm{R}}$ ATCC 43300 & $6.61 \pm 0.20$ & $6.63 \pm 0.09$ & $6.57 \pm 0.10$ & $6.56 \pm 0.19$ & $6.48 \pm 0.31$ & $5.93 \pm 0.16$ & $4.40 \pm 0.13$ \\
E. coli ATCC 25922 & $6.46 \pm 0.35$ & $6.40 \pm 0.46$ & $6.09 \pm 0.26$ & $6.01 \pm 0.22$ & $5.81 \pm 0.78$ & $5.11 \pm 0.30$ & No growth \\
P. aeruginosa ATCC 27853 & $6.82 \pm 0.18$ & $6.57 \pm 0.41$ & $6.74 \pm 0.21$ & $6.42 \pm 0.26$ & $5.33 \pm 0.02$ & $5.22 \pm 0.07$ & $7.75 \pm 0.13$ \\
C. albicans ATCC 90028 & $6.33 \pm 0.18$ & $6.49 \pm 0.09$ & $6.50 \pm 0.12$ & $6.27 \pm 0.10$ & $6.42 \pm 0.17$ & $6.31 \pm 0.08$ & $6.34 \pm 0.15$ \\
\hline
\end{tabular}

$m e t^{S}$ methicillin-susceptible; $m e t^{R}$ methicillin-resistant

not really unexpected, as Pseudomonas' ability to survive and even grow in different antiseptic solutions, including chlorhexidine, has been documented for a long time [24].

\section{Discussion}

With recent reports of emerging resistance to antibiotics, including ampicillin and vancomycin, attention has turned to the use of broad-spectrum antiseptics. In this study, the antimicrobial activity of three different antiseptic ophthalmic preparations was compared for the first time. The microbiological results clearly show the antimicrobial efficacy of povidone-iodine $0.6 \%$ after a short exposure time against all bacterial strains and fungi taken into examination in this experiment.

Povidone-iodine solutions in ocular site disinfection have already been studied on large-scale projects assessing its effectiveness as an antiseptic as well as its safety profile [25].

Compared to most antibiotics, a broad-spectrum antiseptic reduces the likelihood of resistance due to multiple mechanisms of action targeting different characteristics of cell biology [7, 19]. Indeed, despite its long history of efficacious use, no significant cases of microbial resistance to iodine have emerged. In contrast to PVP-I, bacterial resistance to chlorhexidine, quaternary ammonium salts, silver, and triclosan has been documented [7]. Furthermore, numerous studies have shown that PVP-I has a wider antimicrobial spectrum than other available antiseptics [26, 27].

The antiseptic and antiviral activity of ozonized oil in liposomes are well known, and its safety has been assessed in vitro and in vivo [28]. Looking at our results, we might guess that the antimicrobial activity lag was due to an inadequate concentration of the ophthalmic solution that did not reach the MIC and to the presence of liposomes that allow a gradual effect. Indeed, in clinical experience, the administration of OZODROP consists of one eye drop four times a day.

Looking at the number of CFUs after chlorhexidine exposure, it has been suggested that the onset of action of chlorhexidine is less immediate compared with PVP-I [29]. Chlorhexidine is widely used in antiseptic products, at a concentration that ranges from 0.12 in oral rinses to $4 \%$ for hand disinfection $[29,30]$. The low efficacy in vitro observed in this study might be related to the lower concentration of the antiseptic (0.02\%). However, it is necessary to point out that the formulation with the vitamin E TPGS was conceived to provide an encapsulation of chlorhexidine that should improve its absorption towards the corneal stroma but, on the other side, might delay its activity in vitro. In the light of these differences, it is mandatory to understand how the microbial flora on the ocular surface respond in vivo to clarify if the tear film, with its composition and its antibacterial enzymes and antibodies, might induce a different efficacy of the antiseptic molecules [31].

The results would indicate that we should use higher concentration or increase the frequency of the drops instillation to reach an adequate inhibitory concentration.

Our study results emphasize the great efficacy in reducing bacterial load in a very short time of povidone-iodine compared with other antiseptic preparations.

According to these results, the range of indications for topical use of antibiotics might decrease, with PVP-I as the main perioperative antiseptic measure. PVP-I has a rapid antiseptic activity, is readily available worldwide, its use is economically reasonable, and it does not induce microbial resistance. Therefore, PVP-I should outpace the prophylactic antibiotic before any ophthalmic surgical procedure, avoiding the onset of new antibiotic resistance. In patients with iodine allergy, the use of different antiseptic ophthalmic preparations must be taken into account.

Additional studies are required to assess the optimal timing, concentration, and exposure time within different ophthalmic procedures.

Funding Open access funding provided by Università degli Studi di Triestewithin the CRUI-CARE Agreement.

\section{Declarations}

Ethics approval This article does not contain any studies with human participants or animals performed by any of the authors.

Competing interests The authors declare no competing interests. 
Open Access This article is licensed under a Creative Commons Attribution 4.0 International License, which permits use, sharing, adaptation, distribution and reproduction in any medium or format, as long as you give appropriate credit to the original author(s) and the source, provide a link to the Creative Commons licence, and indicate if changes were made. The images or other third party material in this article are included in the article's Creative Commons licence, unless indicated otherwise in a credit line to the material. If material is not included in the article's Creative Commons licence and your intended use is not permitted by statutory regulation or exceeds the permitted use, you will need to obtain permission directly from the copyright holder. To view a copy of this licence, visit http://creativecommons.org/licenses/by/4.0/.

\section{References}

1. Asbell PA, DeCory HH (2018) Antibiotic resistance among bacterial conjunctival pathogens collected in the Antibiotic Resistance Monitoring in Ocular Microorganisms (ARMOR) surveillance study. PLoS ONE 13(10):e0205814

2. Antibiotic resistance (2020) https://www.who.int/news-room/factsheets/detail/antibiotic-resistance. Accessed 31 July 2020

3. Rossolini GM, Arena F, Pecile P, Pollini S (2014) Update on the antibiotic resistance crisis. Curr Opin Pharmacol 18:56-60

4. Huang J, Wang X, Chen X, Song Q, Liu W, Lu L (2016) Perioperative antibiotics to prevent acute endophthalmitis after ophthalmic surgery: a systematic review and meta-analysis. PLoS ONE 11(11):e0166141

5. Menchini F, Toneatto G, Miele A, Donati S, Lanzetta P, Virgili G (2018) Antibiotic prophylaxis for preventing endophthalmitis after intravitreal injection: a systematic review. Eye (Lond) 32(9):1423-1431

6. Grzybowski A, Kanclerz P, Myers WG (2018) The use of povidone-iodine in ophthalmology. Curr Opin Ophthalmol 29(1):19-32

7. Eggers M (2019) Infectious disease management and control with povidone iodine. Infect Dis Ther 8(4):581-593

8. Hashemian H, Mirshahi R, Khodaparast M, Jabbarvand M (2016) Post-cataract surgery endophthalmitis: brief literature review. J Curr Ophthalmol 28(3):101-105

9. Barry P, Cordovés L, Gardner S (2013) ESCRS guidelines for prevention and treatment of endophthalmitis following cataract surgery: prevention \& treatment endophthalmitis. www.escrs.org

10. Shimada H, Nakashizuka H, Grzybowski A (2017) Prevention and treatment of postoperative endophthalmitis using povidoneiodine. Curr Pharm Des 23(4):574-585

11. Musumeci R, Bandello F, Martinelli M, Calaresu E, Cocuzza CE (2019) In vitro bactericidal activity of $0.6 \%$ povidone-iodine eye drops formulation. Eur J Ophthalmol 29(6):673-677

12. Travagli V, Zanardi I, Bocci V (2009) Topical applications of ozone and ozonated oils as anti-infective agents: an insight into the patent claims. Recent Pat Antiinfect Drug Discov 4(2):130-142

13. Cutarelli A, Carlini G, Sarno F et al (2019) The role of ozone carried by liposomes in the therapy of infectious and skin-regenerating ocular surface. J Biomed Sci Eng 12:347-353

14. Finnegan M, Linley E, Denyer SP, McDonnell G, Simons C, Maillard JY (2010) Mode of action of hydrogen peroxide and other oxidizing agents: differences between liquid and gas forms. J Antimicrob Chemother 65(10):2108-2115
15. Celenza G, Iorio R, Cracchiolo S et al (2020) Antimycotic activity of ozonized oil in liposome eye drops against candida spp. Transl Vis Sci Technol 9(8):1-11

16. Merani R, McPherson ZE, Luckie AP (2016) Aqueous chlorhexidine for intravitreal injection antisepsis a case series and review of the literature. Ophthalmology 123(12):2588-2594

17. Seal DV, Hay J, Kirkness CM (1995) Chlorhexidine or polyhexamethylene biguanide for acanthamoeba keratitis. The Lancet 345(8942): 136

18. Oakley C, Allen P, Hooshmand J, Vote BJT (2018) Pain and antisepsis after ocular administration of povidone-iodine versus chlorhexidine. Retina 38(10):2064-2066

19. Lau PE, Jenkins KS, Layton CJ (2018) Current evidence for the prevention of endophthalmitis in anti-VEGF intravitreal injections. J Ophthalmol 2018:8567912

20. Lachapelle JM, Castel O, Casado AF et al (2013) Therapeutic Perspective Antiseptics in the era of bacterial resistance: a focus on povidone iodine. Clin Pr 10(5):579-592

21. Horner C, Mawer D, Wilcox M (2012) Reduced susceptibility to chlorhexidine in staphylococci: is it increasing and does it matter? J Antimicrob Chemother 67(11):2547-2559

22. Grzybowski A, Brona P (2017) Povidone-iodine is still a premium antiseptic measure in ocular surgery. Acta Ophthalmol 95(3):e253-e254

23. Caruso C, Porta A, Tosco A et al (2020) Novel vitamin E TPGSbased formulation enhances chlorhexidine bioavailability in corneal layers. Pharmaceutics 12(7):642

24. Weber DJ, Rutala WA, Sickbert-Bennett EE (2007) Outbreaks associated with contaminated antiseptics and disinfectants. Antimicrob Agents Chemother 51(12):4217-4224

25. Dossarps D, Bron AM, Koehrer P, Aho-Glélé LS, CreuzotGarcher C; FRCR net (FRenCh Retina specialists net) (2015) Endophthalmitis after intravitreal injections: incidence, presentation, management, and visual outcome. Am J Ophthalmol 160(1):17-25.e1

26. Kramer A, Dissemond J, Kim S et al (2018) Consensus on wound antisepsis: update 2018. Skin Pharmacol Physiol 31(1):28-58

27. Kunisada T, Yamada K, Oda S, Hara O (1997) Investigation on the efficacy of povidone-iodine against antiseptic-resistant species. Dermatology 195(Suppl 2):14-18

28. Cagini C, Mariniello M, Messina M et al (2020) The role of ozonized oil and a combination of tobramycin/dexamethasone eye drops in the treatment of viral conjunctivitis: a randomized clinical trial. Int Ophthalmol 40(12):3209-3215

29. Anderson MJ, Horn ME, Lin YC, Parks PJ, Peterson ML (2010) Efficacy of concurrent application of chlorhexidine gluconate and povidone iodine against six nosocomial pathogens. Am J Infect Control 38(10):826-831

30. Williamson DA, Carter GP, Howden BP (2017) Current and emerging topical antibacterials and antiseptics: agents, action, and resistance patterns. Clin Microbiol Rev 30(3):827-860

31. Paulsen F (2008) Functional anatomy and immunological interactions of ocular surface and adnexa. Dev Ophthalmol 41:21-35

Publisher's note Springer Nature remains neutral with regard to jurisdictional claims in published maps and institutional affiliations. 